\title{
Germinação de sementes de Erythrina speciosa Andr., Eugenia brasiliensis Lam. e Cucumis sativus L. em meio ácido
}

\author{
Cristina Rita Radics Koszo ${ }^{1}$, Mirian Cilene Spasiani Rinaldi ${ }^{1}$ e Claudio José Barbedo ${ }^{1,2}$
}

Recebido: 14.09.2006; aceito: 21.06.2007

\begin{abstract}
Germination of seeds of Erythrina speciosa Andr., Eugenia brasiliensis Lam. and Cucumis sativus L. on acid substrate). Many studies have described seed germination as an extremally vulnerable growth phase and seed germinability in response to acidity may subsides the knowledge about the differences in floristic composition. Seeds of two native species from Brazil, Erythrina speciosa Andr. and Eugenia brasiliensis Lam., and a cultivated species (Cucumis sativus L.) were evaluated in relation to their sensibility to acidity and to different aluminium concentration, variable indirect related with the $\mathrm{pH}$ of the soil. Seeds of E. speciosa and C. sativus did not loose germinability even in $\mathrm{pH} 1.0$. Aluminium affectted the germinability of the three species, resulting in total inhibition of germination in $\mathrm{pH} 1.0$ and 2.0. E. brasiliensis showed the greatest sensitivity to environmental chemical conditions. Results showed that the effects of acidity on germination probably affect the phase of the germination process between imbibition and radicle protrusion.
\end{abstract}

Key words: acidity, aluminium, $\mathrm{pH}$, tropical tree species

RESUMO - (Germinação de sementes de Erythrina speciosa Andr., Eugenia brasiliensis Lam. e Cucumis sativus L. em meio ácido). Muitos estudos situam a germinação das sementes dentre os estágios de desenvolvimento extremamente vulneráveis às condições ambientais e que a resposta germinativa à acidez pode auxiliar o conhecimento sobre diferenças na composição florística. Sementes de duas espécies nativas (Erythrina speciosa Andr. e Eugenia brasiliensis Lam.) e uma cultivada (Cucumis sativus L.) foram avaliadas quanto à germinação em diferentes níveis de acidez e a concentrações de alumínio, esta relacionada indiretamente com o $\mathrm{pH}$ do solo. Sementes de E. speciosa e C. sativus germinaram inclusive em $\mathrm{pH} 1,0$. O alumínio afetou a germinação das três espécies, com inibição em pH 1,0 e 2,0. Constatou-se que as sementes de E. brasiliensis apresentaram a maior suceptibilidade às condições químicas do meio. Os resultados demonstraram que o efeito da acidez sobre a germinação provavelmente ocorre entre a fase de embebição e a fase da protrusão da radícula.

Palavras-chave: acidez, alumínio, espécie abórea tropical, $\mathrm{pH}$

\section{Introdução}

A germinação das sementes é o primeiro estágio de desenvolvimento das plantas e as condições ambientais durante essa fase podem afetar o estabelecimento das comunidades vegetais. Dentre essas condições, muitas estão relacionadas com as propriedades do solo no qual a semente é dispersa.

O solo exerce influência direta sobre a germinação das sementes e o metabolismo da planta, através de sua composição física e química. Dentre as propriedades químicas, a acidez do solo é uma característica muito comum em diversas partes do mundo e, principalmente, nas regiões tropicais (Marschner 1986).
A acidez do solo e os demais fatores associados são considerados limitantes ao desenvolvimento das espécies vegetais, pois a concentração hidrogeniônica no ambiente da planta é um dos fatores que afeta sua distribuição (Raij 1987, Bigelow \& Canham 2002). Assim, a distribuição das espécies vegetais pode se correlacionar com as propriedades do solo (Bigelow \& Canham 2002). A diferença nas formações vegetais, com relação ao gradiente de $\mathrm{pH}$ do solo, é resultado de uma seleção natural, na qual as espécies resistentes à acidez, em determinadas situações, têm vantagens competitivas em relação às demais.

Alguns processos naturais são alterados pela acidez, como por exemplo, o entumescimento da semente, que depende do $\mathrm{pH}$ da solução (Zammit \&

1. Instituto de Botânica, Caixa Postal 3005, 01061-970 São Paulo, SP, Brasil

2. Autor para correspondência: claudio.barbedo@pesquisador.cnpq.br 
Zedler 1988) ou o próprio metabolismo celular vegetal, que é dependente da concentração hidrogeniônica (Larcher 2000).

Algumas sementes são incapazes de iniciar ou completar a germinação, devido à dormência por impermeabilidade do tegumento à água, que pode ser eliminada por fatores externos, naturais ou artificiais (Bewley 1997). Em laboratórios de pesquisa, é comum a utilização de ácidos concentrados com a finalidade de simular condições ambientais para superar a dormência devido à impermeabilidade do tegumento e promover a germinação da semente. Contudo, a ação residual do ácido sobre as sementes, seja por meio de sua própria embebição seja pela insuficiente retirada do excesso pela lavagem das sementes, é pouco descrita na literatura. Assim, apesar de amplamente utilizados, os efeitos dos ácidos sobre a germinação das sementes não estão elucidados.

A primeira mudança observada quando as sementes são dispostas a germinar é a embebição, que inclui dois processos simultâneos: a entrada de água na semente e o entumescimento do material interno (Castro et al. 2004), consistindo em um tipo especial de difusão provocada pela atração entre moléculas de água e a superfície matricial (Marcos Filho 2005).

Ao monitorar o conteúdo de água de sementes ortodoxas secas submetidas a embebição em água, muito freqüentemente se observa um padrão típico trifásico de absorção e hidratação (Bewley \& Black 1978, Castro et al. 2004). O período inicial da embebição, quando o embrião começa a absorver água (fase I), apresenta-se meramente como uma hidratação das paredes celulares e colóides citoplasmáticos (Osborne 1983).

A segunda fase (fase II) é caracterizada por uma baixa absorção de água; aparentemente um platô dirigido pelo potencial osmótico. Neste período, as células das sementes não podem mais absorver água porque não podem mais expandir e são ativados os processos metabólicos requeridos para o crescimento do embrião e a conclusão do processo germinativo (Castro et al. 2004). A semente volta a absorver água com intensidade na fase III, concomitantemente com a protrusão da radícula.

A hidratação dos tecidos durante a embebição promove, entre outro eventos, reorganização de organelas e membranas, aumento na atividade respiratória, síntese e consumo de ATP, síntese de proteínas e de mRNAs (Borghetti 2004), síntese e ativação de várias enzimas, resultando na mobilização de reservas (Perez 2004).

As condições químicas do meio podem agir de duas formas sobre a germinação das sementes: ou seu efeito é benéfico e resulta na ativação das reações metabólicas requeridas para a conclusão do processo, ou seu efeito é nocivo e inibe ou reduz a germinação.

A redução da germinação pode ser resultado de estresse ambiental (Foolad et al. 1999). Por esta razão, estudos fitotóxicos dependem da avaliação de respostas germinativas que estão relacionadas à taxa, velocidade e porcentagem de germinação (Dias 2000).

A acidificação e a calagem do solo apresentam efeito relevante sobre a germinação de sementes (Olsson \& Kellner 2002). Contudo, existem divergências entre os autores, pois notam-se variações na resposta germinativa ao $\mathrm{pH}$ entre as diferentes espécies e, algumas vezes, dentro da mesma espécie (Stubbendieck 1974, Redmann \& Abouguendia 1979).

A condição de acidez elevada do solo resulta na dissolução de minerais, tornando, por exemplo, o alumínio disponível e solubilizando-o a ponto de exercer efeito tóxico sobre o desenvolvimento das espécies vegetais (Rout et al. 2001, Ma \& Furukawa 2003). A toxidez de alumínio é o fator limitante mais importante para o crescimento das plantas em solos muito ácidos (Lopes et al. 1998).

O efeito primário ocorre sobre as raízes (Miyasaka \& Hawes 2001), pois o Al age no alongamento (Kochian 1995, Yamamoto et al. 2002) e, principalmente, no processo de divisão celular (Ma et al. 2001).

As membranas celulares alteram-se quando expostas à concentrações de Al. Uma das observações mais comuns é o aumento da permeabilidade, que pode resultar em efluxo de solutos (Vitorello et al. 2005). Além disso, o Al atua degradando proteínas de membranas (Plieth et al. 1999), interferindo nas trocas iônicas, que refletem em distúrbios no status nutricional (Kidd \& Proctor 2000).

A interação do $\mathrm{Al}$ nas reações bioquímicas internas, que alteram os processos fisiológicos, pode resultar em injúrias como enrolamento de folhas novas e colapso do pecíolo, clorose, redução no crescimento, significativa alteração na morfologia da raiz (Kidd \& Proctor 2000, Rout et al. 2001).

Todavia, a ação degenerativa do Al é relativa a diversas variáveis, dentre elas a espécie vegetal em estudo, a espécie química disponível no ambiente, fatores edáficos que podem intensificar ou atenuar 
seu efeito e se o elemento age individualmente ou de forma combinada com outro componente. Em condições de acidez elevada, o alumínio surge em solução, na forma de cátion trocável $\mathrm{Al}^{3+}$, às custas da dissolução de minerais (Raij 1987).

Há algum tempo pesquisadores vêm se dedicando ao estudo dos efeitos do Al, contudo os mecanismos envolvidos na fitotoxidez ainda não foram totalmente esclarecidos (Marschner 1986, Kochian 1995, Yamamoto et al. 2002). As contradições existentes no que se refere aos mecanismos que envolvem os tipos de alumínio não se resumem ao efeito tóxico de cada um, mas também ao comportamento destes quando inter-relacionados às condições edáficas do ambiente em questão, principalmente em relação à acidez do solo.

Erythrina speciosa Andr. é característica e bastante comum da Mata Atlântica, popularmente conhecida como eritrina-candelabro, maçaranduba, mulungu, saranduba ou suinã. Pertence à família Fabaceae (Joly 1970) e é facilmente encontrada nas regiões Sul e Sudeste brasileiras, preferencialmente em solos úmidos e áreas ensolaradas. É espécie arbórea caducifólia, com 3-5 m de altura, apresenta espinhos ao longo do tronco e ramos, possui folhas trifoliadas com exceção dos eófilos que são simples; sua floração ocorre nos meses mais frios do ano, junho a setembro, e as flores vermelhas apresentam cerca de $7 \mathrm{~cm}$ de comprimento e nectários extraflorais. $\mathrm{O}$ tegumento da semente apresenta impermeabilidade à absorção de água, característica bastante comum entre as espécies da família Fabaceae (Lorenzi 1992, Perez 2004). A germinação é epígea, a emissão da radícula ocorre próxima ao hilo e os cotilédones são clorofilados.

Eugenia brasiliensis Lam. é exclusiva da Mata Pluvial Atlântica do sul do Brasil. Espécie arbórea perene, cuja floração ocorre nos meses de setembro a novembro, tem flores brancas de aproximadamente $2 \mathrm{~cm}$ de diâmetro. Existem variedades de frutos amarelos e pretos que são avidamente procurados por aves, tornando a espécie componente indispensável nos reflorestamentos heterogêneos destinados a recomposição de áreas de preservação permanente (Lorenzi 1992). As sementes são caracteristicamente recalcitrantes (Delgado 2006), possuindo elevado conteúdo de água ao serem dispersas. A germinação é hipógea e a emissão da radícula ocorre em regiões não específicas.

Cucumis sativus L., conhecida popularmente como pepino, pertence à família Cucurbitaceae. Possui porte arbustivo e estrutura monóica com padrão de florescimento ao longo da haste principal. O pepino tem crescido em importância na comercialização de hortaliças e tem sido usado como planta teste em experimentos fitotóxicos (Torres et al. 2000). A cultivar Rubi, que apresenta frutos de espinho claros e casca verde-clara, pertencente ao grupo de pepinos denominado Caipira (Barbedo 1990). Espécies cultivadas possuem sensibilidade ao Al em concentrações superiores a 1,0 $\mathrm{mg} \mathrm{L}^{-1}$ (Kidd \& Proctor 2000) e suas sementes geralmente germinam rapidamente.

Assim, o presente trabalho analisou o grau de interferência direta e indireta da acidez sobre a germinação de sementes de Cucumis sativus L., Erythrina speciosa Andr. e Eugenia brasiliensis Lam.

\section{Material e métodos}

Frutos de Erythrina speciosa Andr. foram coletados entre 10 e 19 de novembro de 2004, em quatro parques municipais da cidade de São Paulo: Aclimação, Carmo, Nabuco e Ibirapuera, em mais de dez matrizes. As sementes foram, em seguida, beneficiadas manualmente e homogeneizadas num único lote, sendo retiradas as que se apresentavam chochas. O armazenamento foi feito em sacos de papel, em condição de temperatura e umidade relativa naturais do ambiente de laboratório $\left(22 \pm 7^{\circ} \mathrm{C}\right.$, UR 80 $\pm 20 \%$ ). Devido ao fato das sementes de Erythrina speciosa possuírem dormência física, gerada pela impermeabilidade do tegumento à água, foi necessária a adoção de algum método de escarificação. Baseando-se em resultados de testes prévios, foi realizada uma incisão longitudinal com estilete no tegumento, na região oposta ao hilo, imediatamente antes da instalação do teste de germinação.

Os frutos de Eugenia brasiliensis Lam. foram coletados nos dias 21 e 22 de dezembro de 2004, de duas árvores plantadas no Jardim Botânico de São Paulo. As sementes foram beneficiadas manualmente e armazenadas em câmara fria a $8{ }^{\circ} \mathrm{C}$ e umidade relativa do ar em torno de $45 \%$, em sacos de polietileno transparente perfurado, com o objetivo de impedir o ressecamento.

$\mathrm{O}$ teor de água das sementes de E. speciosa e de E. brasiliensis foi avaliado imediatamente antes do início dos experimentos, pelo método da estufa a $103{ }^{\circ} \mathrm{C}$ por um período de $17 \mathrm{~h}$, segundo recomendações da International Seed Test Association (ISTA 1985). Foram utilizadas quatro repetições de 10 sementes. 
Sementes de Cucumis sativus L. cv. Rubi (Agroflora ${ }^{\circledR}$ ), pela uniformidade genética e sensibilidade às condições do meio para a germinação, foram utilizadas como padrão, sendo adquiridas no comércio em maio de 2005. Segundo seu fabricante, apresentavam $90 \%$ de germinação e $10,6 \%$ de água. Em teste de laboratório, apresentaram 100\% de germinação e $11 \%$ de água. Essas sementes são comercializadas já tratadas com $0,2 \%$ de Thiran. O armazenamento das sementes de C. sativus, a partir de sua compra até o momento das instalações dos testes foi realizado em câmara fria a $8{ }^{\circ} \mathrm{C}$ e umidade relativa do ar em torno de $45 \%$, no próprio recipiente de metal em que são comercializadas.

$\mathrm{O}$ efeito direto da acidez sobre a embebição e a germinação das sementes das três espécies foi avaliado por meio de diferentes níveis de acidificação das soluções de umedecimento do substrato, com três fontes distintas de acidez.

As soluções ácidas utilizadas foram obtidas pela diluição, em água destilada, do ácido sulfúrico $\left(\mathrm{H}_{2} \mathrm{SO}_{4}-98 \%\right.$ P.A. Merck, de densidade $\left.1,84 \mathrm{~g} \mathrm{~cm}^{-3}\right)$ e do ácido nítrico $\left(\mathrm{HNO}_{3}-60 \%\right.$ P.A. Merck, de densidade $1,41 \mathrm{~g} \mathrm{~cm}^{-3}$ ) e pela dissolução do sal cloreto de alumínio $\left(\mathrm{AlCl}_{3}\right)$, este último utilizado também para avaliação de tolerância das sementes ao alumínio. O cloreto de alumínio é freqüentemente adotado em estudos que visam a analisar o efeito tóxico do $\mathrm{Al}$ sobre as espécies vegetais (Taylor et al. 2000, Ma et al. 2001, Miyasaka \& Hawes 2001, Façanha \& Okorokova-Façanha 2002, Ma \& Furukawa 2003, Tamás et al. 2004, Wang et al. 2004, Tamás et al. 2006), não havendo descrição sobre possíveis efeitos do cloro $(\mathrm{Cl})$ destas soluções sobre a germinação das sementes ou sobre o desenvolvimento vegetal.

O tratamento controle constou de água destilada, que apresentou $\mathrm{pH}=6,4$. Os ácidos sulfúrico e nítrico e o cloreto de alumínio foram diluídos para obtenção de $\mathrm{pHs}$ de 1,0 a 5,6. O pH = 5,6 assemelha-se à água da chuva (Haag 1985) e os demais foram adotados seguindo-se modelos metodológicos de pesquisas anteriores com sementes de outras espécies. $\mathrm{O} \mathrm{pH}$ das soluções preparadas foi aferido com pHmêtro Digimed $^{\circledR}$ (modelo DM-20), sendo os valores finais, bem como a molaridade final, apresentados na tabela 1 .

As soluções foram aplicadas aos substratos utilizados nos testes de germinação, sendo sempre repostas quando estes se apresentavam secos. O umedecimento do substrato foi realizado de acordo com a variação na sua capacidade de absorção.
Assim, o substrato foi umedecido até a saturação, sem que houvesse excesso.

Os testes de germinação foram realizados em câmaras ultratermostatizadas Marconi ${ }^{\circledR}$ (MA400), com temperatura constante regulada para $25^{\circ} \mathrm{C}$, luz contínua fornecida por quatro lâmpadas fluorescentes de $20 \mathrm{~W}$ e umidade relativa do ar de $100 \%$, garantida por cortina de água na parede posterior da câmara.

As sementes foram semeadas em placas de Petri de vidro translúcido de $9 \mathrm{~cm}$ de diâmetro, sem tampa, alojadas em caixas plásticas de lateral transparente, de $4 \mathrm{~cm}$ de altura, $19 \mathrm{~cm}$ de largura e $26,5 \mathrm{~cm}$ de comprimento, hermeticamente fechadas, dentro das quais a umidade relativa foi equivalente a $82,2 \%$, determinada por meio de higrômetro portátil .

O substrato constou de uma folha de papel de filtro de fibra de vidro (Glass fiber prefilter) Sartorius ${ }^{\circledR}$, material inerte que, em meio ácido, não se altera por

Tabela 1. Molaridade (M) das soluções obtidas para os diferentes valores de $\mathrm{pH}$, plântulas normais (\%), plântulas anormais (\%) e sementes mortas (\%) de Cucumis sativus L. após germinação em meio acidificado até $\mathrm{pH} 1,0$, por ácido sulfúrico $\left(\mathrm{H}_{2} \mathrm{SO}_{4}\right)$, ácido nítrico $\left(\mathrm{HNO}_{3}\right)$ e cloreto de alumínio $\left(\mathrm{AlCl}_{3}\right)$. O valor de $\mathrm{pH} 6,4$ corresponde ao controle em água. Médias seguidas pela mesma letra (minúscula para comparação nas colunas, maiúsculas nas linhas) não diferem entre si pelo teste de Tukey a 5\%.

\begin{tabular}{|c|c|c|c|}
\hline \multirow{2}{*}{$\begin{array}{l}\text { Acidez da solução } \\
\qquad(\mathrm{pH})\end{array}$} & \multicolumn{3}{|c|}{ Fonte da acidez } \\
\hline & $\mathrm{H}_{2} \mathrm{SO}_{4}$ & $\mathrm{HNO}_{3}$ & $\mathrm{AlCl}_{3}$ \\
\hline & \multicolumn{3}{|c|}{ Molaridade (M) } \\
\hline 1,0 & 0,10 & 0,20 & 3,00 \\
\hline 2,0 & 0,01 & 0,02 & 1,50 \\
\hline 3,5 & $3.10^{-4}$ & $6.10^{-4}$ & 0,05 \\
\hline 5,6 & $3.10^{-6}$ & $6.10^{-6}$ & $4.10^{-5}$ \\
\hline \multicolumn{4}{|c|}{ Plântulas normais } \\
\hline 1,0 & $0 \mathrm{bA}$ & $0 \mathrm{bA}$ & $0 \mathrm{bA}$ \\
\hline 2,0 & $0 \mathrm{bB}$ & $77 \mathrm{aA}$ & $0 \mathrm{bB}$ \\
\hline 3,5 & $54 \mathrm{aB}$ & $73 \mathrm{aA}$ & $0 \mathrm{bC}$ \\
\hline 5,6 & $64 \mathrm{aA}$ & $65 \mathrm{aA}$ & $75 \mathrm{aA}$ \\
\hline 6,4 & $75 \mathrm{aA}$ & $75 \mathrm{aA}$ & $73 \mathrm{aA}$ \\
\hline \multicolumn{4}{|c|}{ Plântulas anormais } \\
\hline 1,0 & $0 \mathrm{cB}$ & $90 \mathrm{aA}$ & $0 \mathrm{cB}$ \\
\hline 2,0 & $96 \mathrm{aA}$ & $22 \mathrm{bB}$ & $0 \mathrm{cC}$ \\
\hline 3,5 & $35 \mathrm{bB}$ & $20 \mathrm{bC}$ & $98 \mathrm{aA}$ \\
\hline 5,6 & $35 \mathrm{bA}$ & $32 \mathrm{bAB}$ & $24 \mathrm{bB}$ \\
\hline 6,4 & $8 \mathrm{cA}$ & $8 \mathrm{cA}$ & $8 \mathrm{cA}$ \\
\hline \multicolumn{4}{|c|}{ Sementes mortas } \\
\hline 1,0 & $100 \mathrm{aA}$ & $10 \mathrm{abB}$ & $100 \mathrm{aA}$ \\
\hline 2,0 & $4 \mathrm{cB}$ & $2 \mathrm{bB}$ & $100 \mathrm{aA}$ \\
\hline 3,5 & $5 \mathrm{cA}$ & $7 \mathrm{bA}$ & $2 \mathrm{cA}$ \\
\hline 5,6 & $1 \mathrm{cA}$ & $3 \mathrm{bA}$ & $2 \mathrm{cA}$ \\
\hline 6,4 & $18 \mathrm{bA}$ & $18 \mathrm{aA}$ & $18 \mathrm{bA}$ \\
\hline
\end{tabular}


reações químicas.

As avaliações nos testes de germinação obedeceram a periodicidade descrita em literatura para cada espécie, registrando-se a porcentagem de sementes germinadas em relação ao número de sementes colocadas para germinar (Borghetti \& Ferreira 2004). Estabeleceu-se, como semente germinada, aquela que apresentasse raiz primária com comprimento maior ou igual a $2 \mathrm{~mm}$. Nas análises germinativas em meio ácido foram adotadas quatro repetições de 16 sementes para Erythrina speciosa e Eugenia brasiliensis. Para Cucumis sativus foram usadas quatro repetições de 20 sementes, devido à maior disponibilidade de sementes.

Para Cucumis sativus, as avaliações de germinação foram realizadas a cada $24 \mathrm{~h}$ devido à sua rapidez em germinar. Os parâmetros de normalidade das plântulas desta espécie foram estimados no $14^{\circ}$ dia para todos os indivíduos, considerando-se aquelas que apresentavam porção aérea (hipocótilo até o ponto de inserção dos cotilédones) desenvolvida e sem deformações, com sistema radicular desenvolvido sem que a raiz primária apresentasse necrose.

Para as sementes de Erythrina speciosa, as avaliações de germinação foram realizadas em dias alternados. No $14^{\circ}$ dia, o substrato no qual as sementes estavam dispostas foi substituído por um novo, ao qual foi adicionada uma solução umedecedora recémcalibrada para os respectivos valores de $\mathrm{pH}$, devido ao grande desenvolvimento de fungos. Como critério de normalidade de plântulas, nesta espécie, consideraram-se os indivíduos que apresentassem parte aérea desenvolvida, sem deformações e com eófilos desembricados, além de apresentar sistema radicular desenvolvido e sem defeitos aparentes. A conclusão das avaliações de germinação para E. speciosa foi realizada no $30^{\circ}$ dia.

As avaliações para Eugenia brasiliensis foram realizadas em dias alternados até o $45^{\circ}$ dia. Plântulas normais, para esta espécie, foram as que possuíam, além de sistema radicular bem desenvolvido, epicótilo superior a $1 \mathrm{~cm}$ de comprimento.

Para avaliar a absorção efetiva dos ácidos pelas sementes por ocasião da embebição em meio ácido, inicialmente analisaram-se curvas de embebição em água pura para que se pudesse estabelecer o momento próximo ao final da fase I da germinação (Bewley \& Black 1985), a partir do qual a embebição torna-se lenta ou quase nula.
Após a determinação do momento próximo ao final da fase I, em horas, três períodos foram definidos para análise da composição química das sementes: inicial (anterior ao início da embebição), final da fase I (embebição final) e metade do período necessário para atingir o final dessa fase I (embebição intermediária). As sementes foram, então, colocadas para embeber nas soluções ácidas e, após as embebições intermediária e final, foram avaliados os teores dos elementos acidificantes nas sementes. Assim, em cada período, para cada espécie, foram avaliadas as concentrações de enxofre (nas sementes embebidas em ácido sulfúrico), de nitrogênio (nas embebidas em ácido nítrico) e de alumínio (nas embebidas em cloreto de alumínio).

As sementes, após a permanência em soluções diluídas de $\mathrm{H}_{2} \mathrm{SO}_{4}, \mathrm{HNO}_{3}$ e $\mathrm{AlCl}_{3}$, foram secas em estufa a $103^{\circ} \mathrm{C}$ por $17 \mathrm{~h}$ (ISTA 1985), posteriormente moídas em moinho e, então, determinaram-se analiticamente os elementos $\mathrm{N}, \mathrm{S}$ e Al.

Para determinação da concentração de nitrogênio, $0,270 \mathrm{~g}$ de sementes maceradas foram colocadas em $8 \mathrm{~mL}$ de solução digestora $\left(10 \mathrm{M} \mathrm{H}_{2} \mathrm{SO}_{4}, 4,5 \mathrm{M} \mathrm{H}_{2} \mathrm{O}_{2}\right.$, $0,14 \mathrm{M} \mathrm{LiSO}_{4}$ e $7 \times 10^{-3} \mathrm{M} \mathrm{Se}$ ) e incubadas a $350{ }^{\circ} \mathrm{C}$ até a completa digestão do material, ou seja, até a obtenção de um líquido incolor. Para a determinação do teor de nitrogênio, após a digestão do material, utilizou-se o método semi-micro-Kjedhal (Malavolta et al. 1997), no qual o nitrogênio presente no produto obtido da digestão, após adição de hidróxido de sódio $18 \mathrm{~N}$, foi destilado na forma de amônia e fixado em solução de ácido bórico $10 \%$, na forma de amônio, e posteriormente titulado com ácido clorídrico $0,1 \mathrm{~N}$, na presença dos indicadores verde de bromo cresol e vermelho de metila. A concentração de nitrogênio foi expressa em mg g de massa seca ${ }^{-1}$.

Para a obtenção da concentração de enxofre e alumínio, fez-se a digestão nítrico-perclórica (Malavolta et al. 1997) de $500 \mathrm{mg}$ do material seco em tubos de ensaio de $100 \mathrm{~mL}$ com $5 \mathrm{~mL}$ de ácido nítrico concentrado e mantidos a temperatura ambiente por uma noite. Os tubos foram então colocados em bloco digestor a $160{ }^{\circ} \mathrm{C}$ por cerca de 30 minutos. Após evaporção de parte do ácido nítrico, os tubos foram retirados do bloco, acrescentando-se 1,3 mL de ácido perclórico concentrado. Os tubos foram colocados novamente no bloco e a temperatura foi aumentada para $210{ }^{\circ} \mathrm{C}$ por mais $15 \mathrm{~min}$. Depois de resfriados, os extratos foram diluídos para um volume final de $50 \mathrm{~mL}$ com água deionizada e 
submetidos às determinações analíticas.

Determinou-se a concentração do enxofre através do método turbidimétrico, que se baseia na turbidez formada pela precipitação do enxofre, com cloreto de bário, formando sulfato de bário. Para tanto, $10 \mathrm{~mL}$ de extrato nítrico-perclórico foram adicionados em $1 \mathrm{~mL}$ de ácido clorídrico $6 \mathrm{~N}$, contendo $20 \mathrm{ppm}$ de enxofre, adicionando-se, a seguir, $500 \mathrm{mg}$ de cloreto de bário. Os frascos contendo essas soluções foram agitados, para manter o precipitado em suspensão, sendo então determinada a turbidez formada pela precipitação do sulfato de bário, a qual foi medida em espectrofotômetro Shimadzu UV-160A, a $470 \mathrm{~nm}$. A concentração de enxofre foi expressa em $\mathrm{mg} \mathrm{g}^{-1}$ de massa seca da semente.

O alumínio foi quantificado em espectrofotômetro de absorção atômica (Shimadzu AA-6601F), com lâmpada de cátodo oco do elemento, utilizando-se chama de alta temperatura. Foram preparadas soluções-padrão estoque utilizando-se o Titrisol MERCK $^{\circledR}$, com 1000 mg do alumínio, e, então, diluído em 1 L de água bi-deionizada. A partir dessa solução, foi preparada a solução-padrão de trabalho, com concentrações de 0 a 15 ppm de Al. Em seguida, foi feita a leitura de absorbância dos padrões e então determinou-se a curva de calibração. Para as amostras, procedeu-se da mesma forma que para as soluçõespadrão.

A comprovação da precisão analítica foi obtida através da digestão de uma amostra do material vegetal padrão com concentrações conhecidas e certificadas de folhas de macieira, n. 1.515, do "National Institute of Standards and Technology", juntamente com as outras amostras.

Em todos os experimentos foi adotado delineamento experimental inteiramente casualizado, em esquema fatorial $3 \times 5$ (fonte de acidez $\times \mathrm{pH}$ da solução) para as avaliações de efeito direto da acidez e $3 \times 3$ (pH da solução $\times$ tempo de embebição) para as curvas de embebição e para estimativa de absorção.

Os dados em porcentagem foram transformados para arc sen $(\% / 100)^{0,5}$, para realização das análises de variância (Teste $\mathrm{F}$, a $5 \%$ de probabilidade) e as médias foram comparadas entre si pelo teste de Tukey, também ao nível de 5\% de probabilidade (Gomes 1982).

\section{Resultados e Discussão}

A análise dos resultados da germinação de Cucumis sativus L. permitiu verificar que houve interação significativa entre o pH da solução de embebição e a fonte de acidez (figura 1). Para soluções com pH de 6,4 (água pura) a 3,5 não se observou alteração na capacidade germinativa das sementes, independentemente da fonte de acidez $\left(\mathrm{H}_{2} \mathrm{SO}_{4}, \mathrm{HNO}_{3}\right.$ ou $\left.\mathrm{AlCl}_{3}\right)$.

Por outro lado, em pH 2,0, apenas houve prejuízo à germinação quando o alumínio foi empregado como fonte de acidez, resultando na completa perda da capacidade germinativa das sementes. Isso pode ser explicado pela quantidade do elemento no meio pois, segundo Iqbal \& Shafiq (2003), a resposta das plantas aos metais é dose dependente. No mesmo valor de $\mathrm{pH}$, soluções compostas por $\mathrm{H}_{2} \mathrm{SO}_{4}$ ou $\mathrm{HNO}_{3}$ não alteraram a capacidade germinativa das sementes. Reduzindo-se ainda mais o valor de $\mathrm{pH}$ para 1,0, apenas na solução preparada com ácido nítrico verificou-se germinação dessas sementes (figura 1).

Esses resultados sugerem que a fonte responsável pela produção da acidez pode ter igual ou maior influência sobre a germinação das sementes do que a própria acidez. A diferença observada entre os resultados de germinação quando as sementes foram submetidas ao ácido sulfúrico e ao ácido nítrico em pH 1,0 (figura 1) já era esperada, uma vez que o ácido sulfúrico dissocia, reconhecidamente, maior quantidade de $\mathrm{H}^{+}$para o meio (Quagliano \& Vallarino 1973). Contudo, o mesmo não se aplicaria ao $\mathrm{AlCl}_{3}$, cujo efeito apareceu em $\mathrm{pH}$ 2,0. Neste caso, três efeitos podem ter gerado a perda da capacidade germinativa, associados ou não com a acidez propriamente dita: i) o efeito tóxico do $\mathrm{Al}^{3+}$ (Rout et al. 2001, Iqbal \& Shafiq 2003); ii) o efeito tóxico do $\mathrm{Cl}^{-}$(Fonseca \& Perez 2001) ou iii) o elevado potencial osmótico da solução (Torres et al. 2000). Para esta última hipótese, é importante salientar que o potencial osmótico das soluções de $\mathrm{H}_{2} \mathrm{SO}_{4}$ e de $\mathrm{HNO}_{3}$ situou-se sempre entre zero e - $0,5 \mathrm{MPa}$, mesmo nas soluções com $\mathrm{pH} 1,0$, potenciais esses que se mostraram como não limitantes ao fornecimento de água para as sementes (Torres et al. 2000). Já para as soluções de $\mathrm{AlCl}_{3}$, até $\mathrm{pH} 3,5$ o potencial hídrico também ficou acima de $-0,5 \mathrm{MPa}$ mas, em $\mathrm{pH}$ 2,0, diminuiu para -24,0 MPa.

Analisando-se os resultados da tabela 1 nota-se que há grande aumento da porcentagem de plântulas anormais antes da completa perda da capacidade germinativa das sementes. Esse aumento ocorreu em $\mathrm{pH} 5,6$ e 3,5, quando empregado o $\mathrm{AlCl}_{3}$, mas em valores mais baixos de $\mathrm{pH}(1,0$ a 2,0$)$ quando se 
utilizaram soluções de $\mathrm{H}_{2} \mathrm{SO}_{4}$ e $\mathrm{HNO}_{3}$. Tal fato poderia indicar efeito tóxico de $\mathrm{Cl}^{-}$ou $\mathrm{Al}^{3+}$. Apesar de terem sido realizados alguns estudos avaliando efeitos tóxicos da salinidade em sementes (Santos et al. 1992, Torres et al. 2000, Fonseca \& Perez 2001), pouco

A

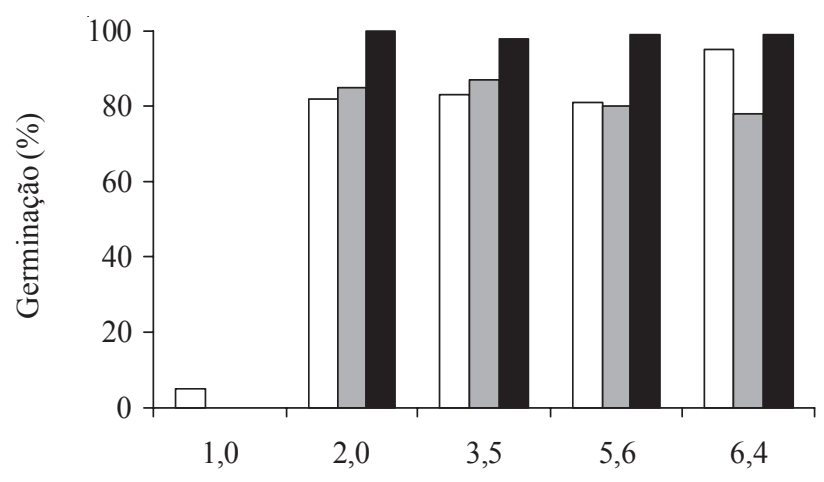

$\mathrm{B}$
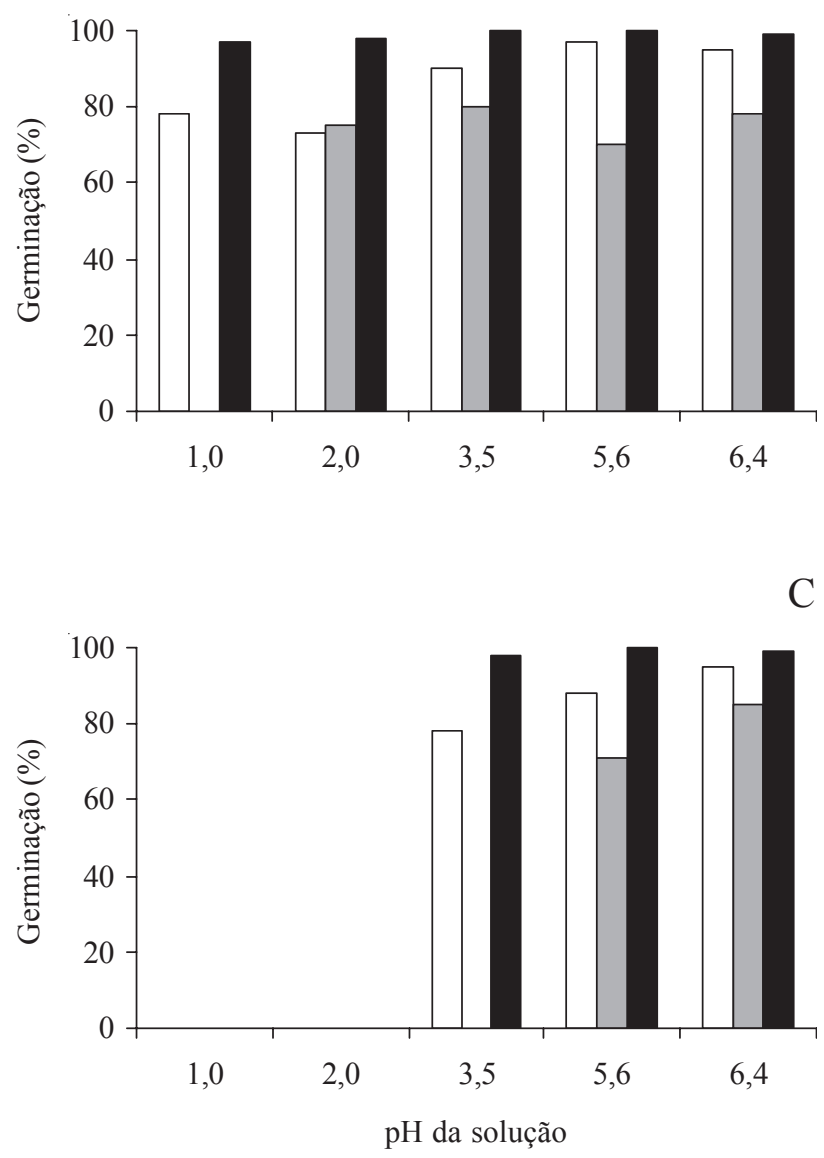

Figura 1. Germinação (\%) de sementes de Erythrina speciosa Andr. ( $\square$ ), Eugenia brasiliensis Lam. ( $\square$ ) e Cucumis sativus L. (ם) em soluções diluídas de ácido sulfúrico (A), ácido nítrico (B) e cloreto de alumínio (C). ainda se conhece efetivamente sobre o efeito do cloro, justificando o desenvolvimento de pesquisas com esse objetivo específico. Por outro lado, vários estudos demonstraram os efeitos tóxicos do $\mathrm{Al}^{3+}$ na germinação das sementes e, principalmente, no desenvolvimento inicial das plântulas (Rout et al. 2001), como os observados no presente trabalho, frequentemente empregando o cloreto de alumínio como fonte deste último (Taylor et al. 2000, Ma et al. 2001, Miyasaka \& Hawes 2001, Façanha \& Okorokova-Façanha 2002, Ma \& Furukawa 2003, Tamás et al. 2004, Wang et al. 2004, Tamás et al. 2006).

Pelos resultados apresentados na figura 2 é possível verificar que houve absorção de alumínio pelas sementes embebidas em solução $\mathrm{AlCl}_{3}$ a partir do $\mathrm{pH}$ 3,5 , aumentando expresssivamente no $\mathrm{pH} 2,0$, já na metade do tempo necessário para que as sementes atingissem o final da fase I da germinação, descrita por Bewley \& Black (1985). Portanto, efeitos tóxicos do alumínio, caso existam, podem se manifestar já a partir do $\mathrm{pH} 3,5$ e antes de se iniciar a fase III da germinação, na qual ocorre protrusão da raiz primária. Segundo Rout et al. (2001), o alumínio não afeta a germinação das sementes, mas pode inibir o início do crescimento da raiz primária e, segundo Tamás et al. (2004), ocasionar danos no sistema de membranas celulares. Em relação aos ácidos nítrico e sulfúrico, mesmo em pH 2,0 ou 1,0, que causaram prejuízos à germinação das sementes, não houve absorção desses ácidos, conforme demonstrado na figura 2 .

Da mesma forma que o verificado para a germinação de sementes de $C$. sativus em substratos com diferentes soluções ácidas e diferentes valores de $\mathrm{pH}$, também para as sementes de Erytrhina speciosa a análise estatística indicou interação significativa entre os fatores. Os resultados apresentados na figura 1 e na tabela 2 indicam que não houve alteração significativa na capacidade germinativa das sementes entre os pHs 6,4 e 3,5, independentemente da fonte da acidez. Novamente se verifica que, a partir de valores de $\mathrm{pH}$ inferiores a 3,5, os efeitos da acidez são dependentes da fonte, com perda completa da capacidade germinativa em pH 2,0, para soluções formadas por cloreto de alumínio e quase completa perda em $\mathrm{pH} 1,0$, quando em ácido sulfúrico. Conforme discutido anteriormente, talvez pela menor quantidade de $\mathrm{H}^{+}$ dissociada a partir do ácido nítrico, em relação ao sulfúrico, as sementes desta espécie também não 
tiveram sua capacidade germinativa afetada por aquele ácido nem em $\mathrm{pH}$ 1,0.

Em sementes de E. speciosa não se verificou o efeito tóxico do alumínio em $\mathrm{pH}$ 3,5 pois, enquanto as sementes de $C$. sativus apresentaram alta porcentagem de plântulas anormais, nesta espécie se
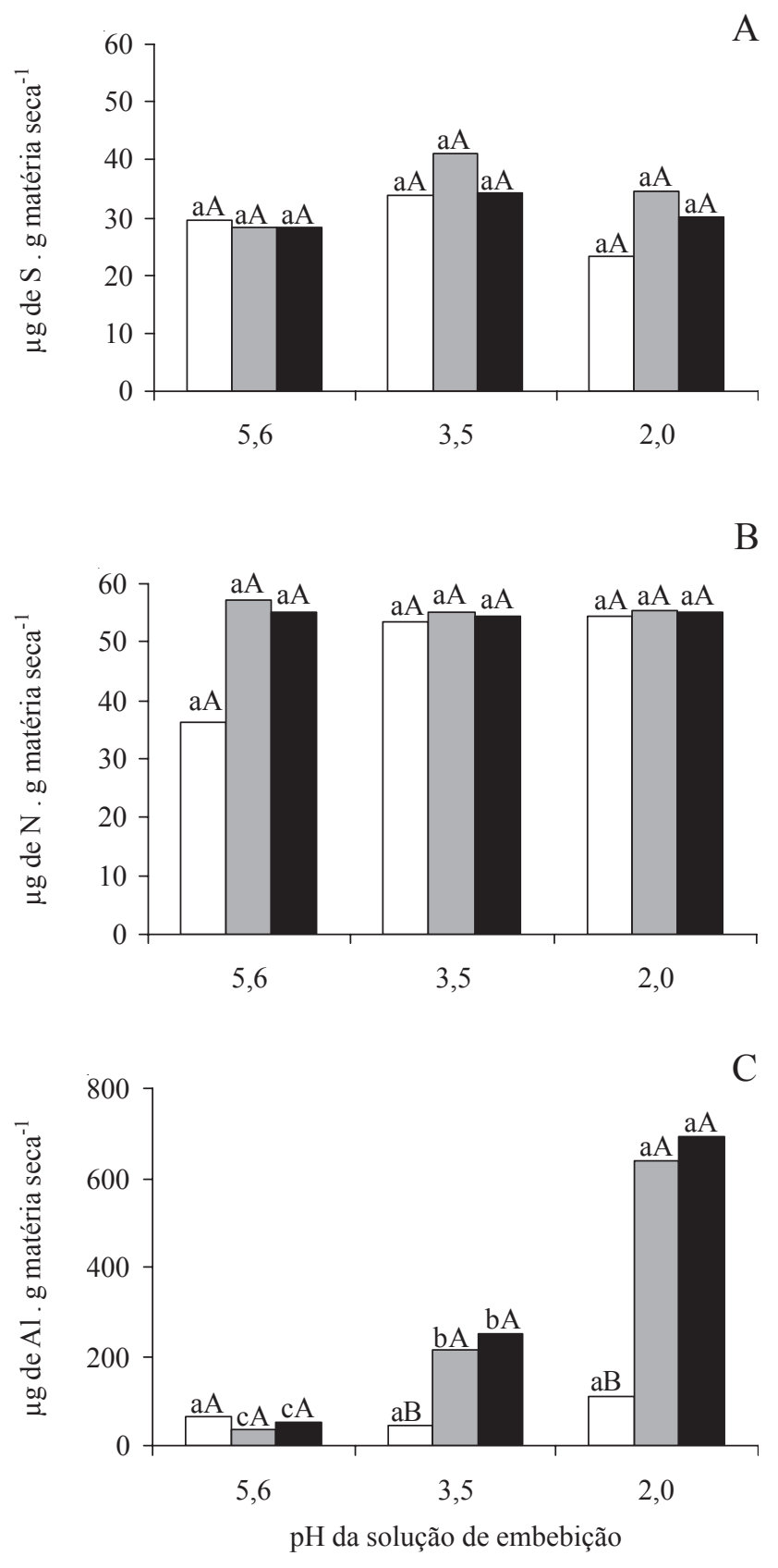

Figura 2. Média da absorção de enxofre (S), nitrogênio (N) e alumínio (Al) pelas sementes de Cucumis sativus L. no início ( $\square$ ) e após dois períodos de embebição ( $\square$ : intermediária; $\square$ : final), nas soluções de ácido sulfúrico (A), ácido nítrico (B) e cloreto de alumínio (C). Valores seguidos de mesma letra (minúsculas comparam níveis de $\mathrm{pH}$ e maiúsculas tempo de embebição) não diferem entre si pelo teste de Tukey $(5 \%)$.
Tabela 2. Plântulas normais (\%), plântulas anormais (\%) e sementes mortas (\%) de Erythrina speciosa Andr. após germinação em meio acidificado até $\mathrm{pH} 1,0$, por ácido sulfúrico $\left(\mathrm{H}_{2} \mathrm{SO}_{4}\right)$, ácido nítrico $\left(\mathrm{HNO}_{3}\right)$ e cloreto de alumínio $\left(\mathrm{AlCl}_{3}\right)$. O valor de pH6.4 corresponde ao controle em água. Médias seguidas pela mesma letra (minúscula para comparação nas colunas, maiúsculas nas linhas) não diferem entre si pelo teste de Tukey a $5 \%$.

\begin{tabular}{cccr}
\hline \multirow{2}{*}{$\begin{array}{c}\text { Acidez da solução } \\
(\mathrm{pH})\end{array}$} & \multicolumn{3}{c}{ Fonte da acidez } \\
\cline { 2 - 4 } & $\mathrm{H}_{2} \mathrm{SO}_{4}$ & $\mathrm{HNO}_{3}$ & $\mathrm{AlCl}_{3}$ \\
\hline \multicolumn{4}{c}{ Plântulas normais } \\
1,0 & $0 \mathrm{cB}$ & $25 \mathrm{cA}$ & $0 \mathrm{cB}$ \\
2,0 & $44 \mathrm{bA}$ & $42 \mathrm{bA}$ & $0 \mathrm{cB}$ \\
3,5 & $58 \mathrm{abA}$ & $52 \mathrm{abA}$ & $32 \mathrm{bB}$ \\
5,6 & $56 \mathrm{abA}$ & $57 \mathrm{abA}$ & $43 \mathrm{bB}$ \\
6,4 & $80 \mathrm{aA}$ & $80 \mathrm{aA}$ & $80 \mathrm{aA}$ \\
& & Plântulas anormais \\
1,0 & $0 \mathrm{bB}$ & $17 \mathrm{aA}$ & $0 \mathrm{bB}$ \\
2,0 & $28 \mathrm{aA}$ & $15 \mathrm{aB}$ & $0 \mathrm{bC}$ \\
3,5 & $17 \mathrm{abAB}$ & $13 \mathrm{aB}$ & $23 \mathrm{aA}$ \\
5,6 & $15 \mathrm{abA}$ & $23 \mathrm{aA}$ & $25 \mathrm{aA}$ \\
6,4 & $10 \mathrm{bA}$ & $10 \mathrm{aA}$ & $10 \mathrm{abA}$ \\
& & Sementes mortas & \\
1,0 & $100 \mathrm{aA}$ & $58 \mathrm{aB}$ & $100 \mathrm{aA}$ \\
2,0 & $26 \mathrm{bC}$ & $40 \mathrm{bB}$ & $100 \mathrm{aA}$ \\
3,5 & $22 \mathrm{bB}$ & $35 \mathrm{cA}$ & $42 \mathrm{bA}$ \\
5,6 & $28 \mathrm{bA}$ & $15 \mathrm{~dB}$ & $23 \mathrm{cA}$ \\
6,4 & $10 \mathrm{cA}$ & $10 \mathrm{dA}$ & $10 \mathrm{dA}$ \\
\hline
\end{tabular}

observou uma situação em que proporções similares das sementes germinaram e produziram plântulas normais, ou nem germinaram. Erythrina speciosa é espécie nativa da Mata Atlântica brasileira, cujos solos apresentam elevada concentração de alumínio (Carvalho et al. 1980, Resende et al. 2002). Talvez por esse motivo, suas sementes contém, em média, concentração natural de alumínio superior à observada em sementes de C. sativus $\left(133,3 \mu \mathrm{g} \mathrm{g}^{-1} \mathrm{em}\right.$ E. speciosa e $73,3 \mu \mathrm{g} \mathrm{g}^{-1}$ em C. sativus). Além disso, a concentração de alumínio nas sementes de E. speciosa só aumentou quando houve embebição em solução de $\mathrm{AlCl}_{3}$ pH 2,0 (figura 3), o que pode indicar algum grau de tolerância a esse elemento.

A variação de tolerância ao alumínio entre sementes de diferentes espécies pode ser constatada em outros trabalhos. Em sementes de Picea glauca Moench. (Nosko et al. 1987), Picea rubens Sarg., Abies balsamea L., Betula alleghaniensis Britt. e Betula papyrifera Marsh. (Scherbatskoy et al. 1987), por exemplo, não se verificou efeito tóxico ou inibidor da germinação, enquanto em sementes de Triticum aestivum L. cv. Blue Silver (Iqbal \& Shafiq 2003), Succisa pretensis, Rhyncosphora alba, Parnassia 
palustris, Euphrasia stricta, Gentiana pneumonanthe e Epipactis palustris (Roem et al. 2002), verificou-se efeito prejudicial do alumínio.

De forma semelhante ao obtido para Cucumis sativus e Erythrina speciosa, o tratamento $\mathrm{H}_{2} \mathrm{SO}_{4}$ pH 1,0 inibiu a germinação das sementes de Eugenia
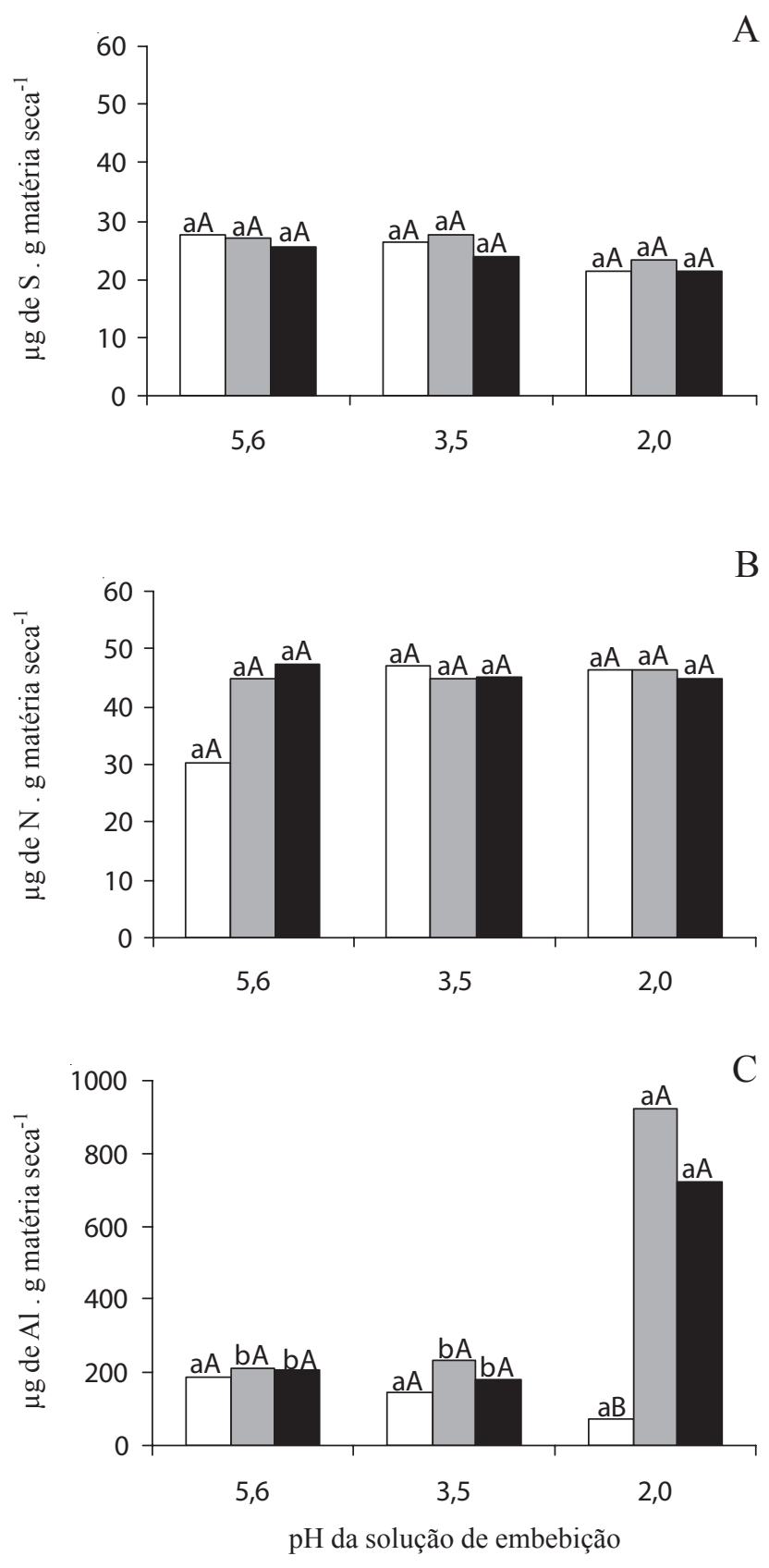

Figura 3. Média da absorção de enxofre (S), nitrogênio $(\mathrm{N})$ e alumínio (Al), pelas sementes Erythrina speciosa Andr. no início $(\square)$ e após dois períodos de embebição ( $\square$ : intermediária; $\mathbf{\square}$ : final), nas soluções de ácido sulfúrico (A), ácido nítrico (B) e cloreto de alumínio (C). Valores seguidos de mesma letra (minúsculas comparam níveis de $\mathrm{pH}$ e maiúsculas tempo de embebição) não diferem entre si pelo teste de Tukey (5\%). brasiliensis Lam. (figura 1 e tabela 3). Contudo, diferentemente do que se verificou nas sementes das espécies anteriores, houve efeito prejudicial à germinação de $E$. brasiliensis quando se utilizou ácido nítrico, o que reflete uma maior sensibilidade desta espécie à acidez. Novamente confirmam-se observações anteriores quanto às variações na sensibilidade das sementes de diferentes espécies à acidez (Stubbendieck 1974, Chachalis \& Reddy 2000, Roem et al. 2002, Murata et al. 2003). Confirmando a dificuldade de absorção dos ácidos pelas sementes, também em E. brasiliensis não houve aumento no conteúdo de enxofre ou de nitrogênio quando a embebição foi realizada, respectivamente, em soluções de ácido sulfúrico e ácido nítrico (figura 4).

Outra importante diferença observada no comportamento das sementes de E. brasiliensis em relação àquela observada nas sementes das outras espécies diz respeito à resposta germinativa ao alumínio. Enquanto nas sementes de C. sativus e de E. speciosa as soluções de cloreto de alumínio prejudicaram a germinabilidade apenas em $\mathrm{pH} 2,0 \mathrm{ou}$ inferior, nas de E. brasiliensis houve prejuízo já a partir de $\mathrm{pH} 3,5$, com completa perda da capacidade

Tabela 3. Plântulas normais (\%), plântulas anormais (\%) e sementes mortas (\%) de Eugenia brasiliensis Lam. após germinação em meio acidificado até $\mathrm{pH} 1,0$, por ácido sulfúrico $\left(\mathrm{H}_{2} \mathrm{SO}_{4}\right)$, ácido nítrico $\left(\mathrm{HNO}_{3}\right)$ e cloreto de alumínio $\left(\mathrm{AlCl}_{3}\right)$. O valor de $\mathrm{pH} 6.4$ corresponde ao controle em água. Médias seguidas pela mesma letra (minúscula para comparação nas colunas, maiúsculas nas linhas) não diferem entre si pelo teste de Tukey a 5\%.

\begin{tabular}{cccr}
\hline \multirow{2}{*}{$\begin{array}{c}\text { Acidez da solução } \\
(\mathrm{pH})\end{array}$} & \multicolumn{3}{c}{ Fonte da acidez } \\
\cline { 2 - 4 } & $\mathrm{H}_{2} \mathrm{SO}_{4}$ & $\mathrm{HNO}_{3}$ & $\mathrm{AlCl}_{3}$ \\
\hline \multicolumn{4}{c}{ Plântulas normais } \\
1,0 & $0 \mathrm{dA}$ & $0 \mathrm{cA}$ & $0 \mathrm{bA}$ \\
2,0 & $49 \mathrm{bA}$ & $52 \mathrm{aA}$ & $0 \mathrm{bB}$ \\
3,5 & $76 \mathrm{aA}$ & $58 \mathrm{aB}$ & $0 \mathrm{bC}$ \\
5,6 & $71 \mathrm{aA}$ & $50 \mathrm{aB}$ & $37 \mathrm{aC}$ \\
6,4 & $26 \mathrm{cA}$ & $26 \mathrm{bA}$ & $26 \mathrm{aA}$ \\
& & Plântulas anormais & \\
1,0 & $0 \mathrm{aA}$ & $0 \mathrm{bA}$ & $0 \mathrm{bA}$ \\
2,0 & $10 \mathrm{aAB}$ & $22 \mathrm{aA}$ & $0 \mathrm{bB}$ \\
3,5 & $9 \mathrm{aAB}$ & $15 \mathrm{abA}$ & $0 \mathrm{bB}$ \\
5,6 & $15 \mathrm{aB}$ & $27 \mathrm{aA}$ & $32 \mathrm{aA}$ \\
6,4 & $20 \mathrm{aA}$ & $20 \mathrm{abA}$ & $20 \mathrm{abA}$ \\
& & Sementes mortas & \\
1,0 & $100 \mathrm{aA}$ & $0 \mathrm{bB}$ & $100 \mathrm{aA}$ \\
2,0 & $9 \mathrm{bB}$ & $0 \mathrm{bB}$ & $100 \mathrm{aA}$ \\
3,5 & $1 \mathrm{bB}$ & $0 \mathrm{bB}$ & $100 \mathrm{aA}$ \\
5,6 & $0 \mathrm{bA}$ & $32 \mathrm{aA}$ & $0 \mathrm{bA}$ \\
6,4 & $0 \mathrm{bA}$ & $0 \mathrm{bA}$ & $0 \mathrm{bA}$ \\
\hline
\end{tabular}


germinativa (figura 1 e tabela 3). Tal fato reforça a maior sensibilidade das sementes de E. brasiliensis ao alumínio.

Considerando-se os resultados apresentados na figura 1 e na tabela 3 e o fato dessas sementes serem intolerantes à dessecação (Delgado 2006), iniciando

A

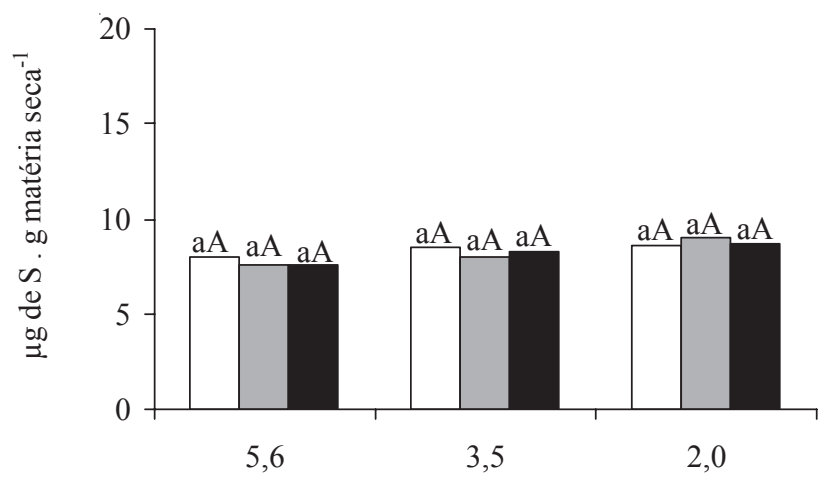

B

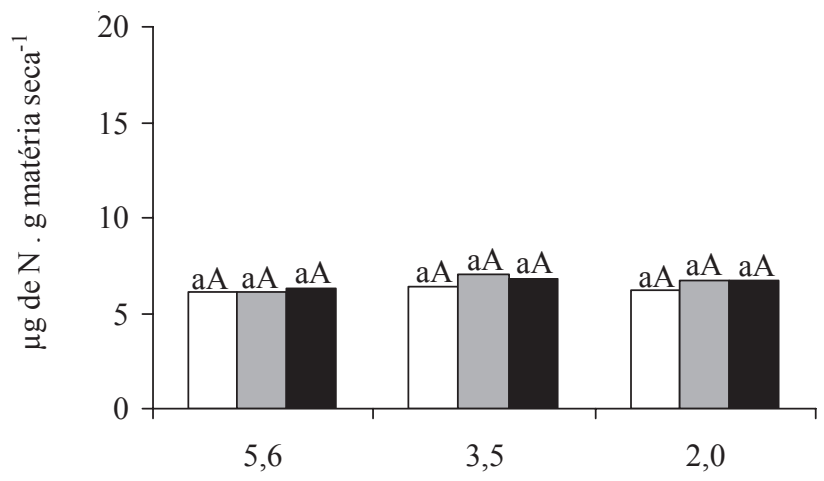

$\mathrm{C}$

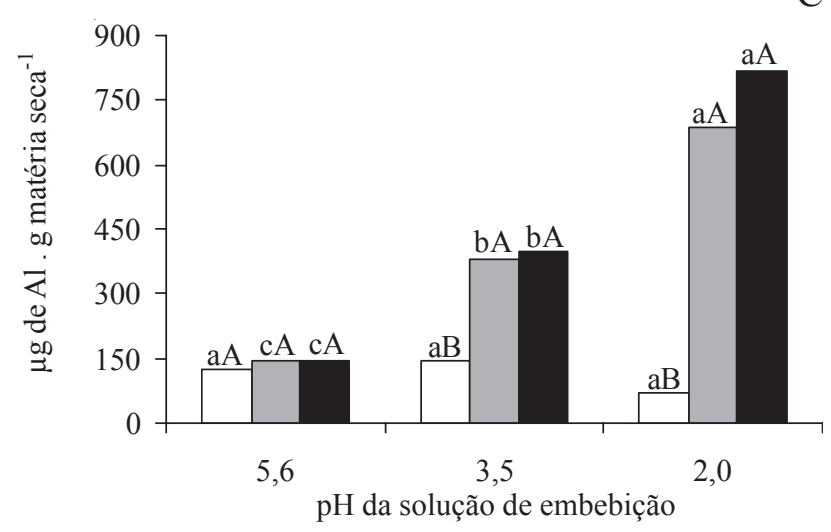

Figura 4. Média da absorção de enxofre (S), nitrogênio $(\mathrm{N})$ e alumínio (Al), pelas sementes Eugenia brasiliensis Lam. no início $(\square)$ e após dois períodos de embebição ( $\square$ : intermediária; final), nas soluções de ácido sulfúrico (A), ácido nítrico (B) e cloreto de alumínio (C). Valores seguidos de mesma letra (minúsculas comparam níveis de $\mathrm{pH}$ e maiúsculas tempo de embebição) não diferem entre si pelo teste de Tukey (5\%). os testes de germinação com elevado teor de água, reforça-se a idéia do potencial efeito tóxico do alumínio na germinação de sementes. Na solução de cloreto de alumínio com $\mathrm{pH}$ 3,5, conforme descrito anteriormente, tem-se potencial osmótico superior a $-0,5 \mathrm{MPa}$. Sementes de E. brasiliensis com teor de água próximo a $40 \%$, como as utilizadas no presente trabalho, têm potencial hídrico entre $-2,0$ a $-4,0 \mathrm{MPa}$ (Delgado 2006). Como a água se move espontaneamente de uma zona de potencial químico mais elevado para outra de potencial mais baixo (Leopold \& Vertucci 1989), as sementes de E. brasiliensis teriam suficiente água livre na solução de alumínio a $\mathrm{pH}$ 3,5 para que não houvesse efeito osmótico sobre a germinação, diferentemente do que ocorre na solução a pH 2,0. Somam-se a esse fato os resultados de absorção de alumínio pelas sementes de E. brasiliensis (figura 4), demonstrando substancial aumento na quantidade de alumínio nas sementes submetidas à solução de cloreto de alumínio de $\mathrm{pH} 3,5$, praticamente o dobro da quantidade observada nas sementes das outras espécies.

Conforme descrito por Kochian (1995), há danos fisiológicos e morfológicos visíveis em plantas expostas a elevadas concentrações de alumínio mas, segundo Ma et al. (2001), mesmo em concentrações micromolares o alumínio pode inibir o crescimento radicular. Considerando-se que para as sementes das três espécies estudadas no presente trabalho houve absorção de alumínio nas soluções com pH 3,5 ou inferior, pode-se supor que não há necessidade das sementes atingirem a fase III da germinação (Bewley \& Black 1985), com crescimento visível da raiz primária, para que se iniciem os efeitos do alumínio, como descrito por Rout et al. (2001), mas que tais efeitos poderiam se iniciar já na fase II. Esse seria, evidentemente, um efeito indireto da acidez sobre a germinação das sementes, uma vez que o pH modifica a solubilidade do alumínio na solução do solo, aumentando esta solubilidade com a diminuição do $\mathrm{pH}$ (Ma et al. 2001).

Além disso, é importante destacar o efeito direto da acidez sobre a germinação das sementes, embora tenha sido demonstrado, no presente trabalho, que esse efeito só ocorreria em situações pouco prováveis em condições naturais, ou seja, com a solução do solo apresentando $\mathrm{pH}$ igual ou inferior a 1,0 e, ainda assim, com a presença de ácidos específicos. Essa situação seria mais provável de ser encontrada nas práticas de escarificação química de sementes. 
Os resultados do presente trabalho permitiram concluir que sementes de Cucumis sativus L., Erythrina speciosa Andr. e Eugenia brasiliensis Lam. podem germinar em meio ácido, desde que o pH não seja inferior a 2,0. O aumento da concentração de alumínio, como efeito indireto da acidez do meio, pode prejudicar a germinação das sementes dessas espécies e o desenvolvimento inicial das plântulas.

\section{Agradecimentos}

Este trabalho é parte da dissertação de Mestrado de C.R.R. Koszo. Ao Conselho Nacional do Desenvolvimento Científico e Tecnológico (CNPq), pela bolsa de produtividade em pesquisa concedida a C.J. Barbedo; à Fundação de Amparo a Pesquisa do Estado de São Paulo (FAPESP), pelo apoio financeiro a parte do projeto (processo 2002/12215-7); ao Departamento de Parques e Áreas Verdes do Município de São Paulo (DEPAVE) e ao Jardim Botânico de São Paulo pelas sementes utilizadas no trabalho.

\section{Literatura citada}

Barbedo, C.J. 1990. Influência da idade e do repouso pós colheita de frutos na qualidade fisiológica de sementes de pepino (Cucumis sativus L.). Dissertação de Mestrado, Universidade Estadual Paulista, Botucatu.

Bewley, D.J. 1997. Seed germination and dormancy. The Plant Cell 9: 1055-1066.

Bewley, D.J. \& Black, M. 1978. Seeds: physiology of development and germination. Journal of Ecology 74: 905-906.

Bewley, D.J. \& Black, M. 1985. Seeds physiology of development and germination. Plenum Press, New York.

Bigelow, S.W. \& Canham, C.D. 2002. Comunity organization of tree species along soil gradients in a north-eastern USA forest. Journal of Ecology 90: 188-200.

Borghetti, F. 2004. Dormência embrionária. In: A.G. Ferreira \& F. Borghetti (orgs). Germinação: do básico ao aplicado. Artmed, Porto Alegre, pp.109-125.

Borghetti, F. \& Ferreira, A.G. 2004. Interpretação de resultados de germinação. In: A.G. Ferreira \& F. Borghetti (orgs.). Germinação: do básico ao aplicado. Artmed, Porto Alegre, pp. 209-222.

Carvalho, N.M., Demattê, M.E.S.P. \& Graziano, T.T. 1980. Germinação de sementes de essências florestais nativas: suinã ou mulungu (Erythrina speciosa Andr.). Revista Brasileira de Sementes 2: 81-88.
Castro, R.D., Bradford, K.J. \& Hilhorst, H.W.M. 2004. Embebição e reativação do metabolismo. In: A.G. Ferreira \& F. Borghetti (orgs.). Germinação: do básico ao aplicado. Artmed, Porto Alegre, pp. 149-162.

Chachalis, D. \& Reddy, K.N. 2000. Factors affecting Campsis radicans seed germination and seedling emergence. Weed Science 48: 212-216.

Delgado, L.F. 2006. Tolerância à dessecação em sementes de espécies brasileiras de Eugenia. Dissertação de Mestrado, Instituto de Botânica, São Paulo.

Dias, L. 2000. Describing phytotoxic effect on cumulative germination. Journal of Chemical Ecology 27: 411-418.

Façanha, A.R. \& Okorokova-Façanha, A.L. 2002. Inibition of phosphate uptake in corn roots by aluminum-fluoride complexes. Plant Physiology 129: 1763-1772.

Fonseca, S.C.L. \& Perez, S.C.J.G.A. 2001. Germinação de sementes de olho-de-dragão (Adananthera pavonina L.): ação de poliaminas na atenuação do estresse salino. Revista Brasileira de Sementes 23: 14-20.

Foolad, M.R., Hyman, J.R. \& Lin, G.Y. 1999. Relationships between cold- and salt-tolerance during seed germination in tomato: Analysis of response and correlated response to selection. Plant Breeding 118: 49-52.

Gomes, F.P. 1982. Curso de estatística experimental. 10 ed. Nobel, Piracicaba.

Haag, H.P. 1985. Chuvas ácidas. Fundação Cargill, Campinas.

Iqbal, M.Z. \& Shafiq, M. 2003. Effects of aluminium on germination and growth of two diferent wheat cultivars. Acta Botanica Hungarica 45: 315-321.

ISTA. 1985. International rules for seed testing. Seed Science and Tecnology 13: 356-513.

Joly, A.B. 1970. Botânica: chaves de identificação das famílias de plantas vasculares que ocorrem no Brasil. Companhia Editora Nacional, Rio de Janeiro.

Kidd, P.S. \& Proctor, J. 2000. Effect of aluminium on the growth and mineral composition of Betula pendula Roth. Journal of Experimental Botany 51: 1057-1066.

Kochian, L.V. 1995. Celular mechanism of aluminium toxicity and resistance in plants. Annual Review of Plant Physiology 46: 237-260.

Larcher, W. 2000. Ecofisiologia vegetal. Editora Rima, São Carlos.

Leopold, A.C. \& Vertucci, C.W. 1989. Moisture as a regulator of physiological reaction in seeds. In: P.C. Stanwood \& M. McDonald (eds). Seed Moisture. Crop Science Society of America, Madison, pp. 51-67. 
Lopes, C.J., Capucho, M.T. \& Zanotti, P. 1998. Germinação de sementes de espécies florestais de Caesalpinea ferrea Mart. Ex Tul. var. leiostachya Benth., Cassia grandis L. e Samanea saman Merrill, após tratamento para superar a dormência. Revista Brasileira de Botânica 20: 80-86.

Lorenzi, H. 1992. Árvores brasileiras: Manual de identificação e cultivo de plantas arbóreas nativas do Brasil. Plantarum, Nova Odessa.

Ma, J.F. \& Furukawa, J. 2003. Recent progress in the research of external Al detoxification on higher plants: a minireview. Journal of Inorganic Biochemistry 97: 46-51.

Ma, J.F., Ryan, P.R. \& Delhaize, E. 2001. Aluminium tolerance in plants and complexing role of organic acids. Trends in Plant Science 6: 273-278.

Malavolta, E, Vitti, G.C. \& Oliveira, S.A. 1997. Avaliação do estado nutricional das plantas: princípios e aplicações. 2 ed. Potafós, Piracicaba.

Marcos Filho, J. 2005. Fisiologia de sementes de plantas cultivadas. Fealq, Piracicaba.

Marschner, H. 1986. Mineral nutrition of higher plants. Academic Press, London.

Miyasaka, S.C. \& Hawes, M.C. 2001. Possible role of border cells in detection and avoidance of aluminium toxicity. Plant Physiology 125: 1978-1987.

Murata, M.R., Hammes, P.S. \& Zharare, G.E. 2003. Effect of solution $\mathrm{pH}$ and calcium concentration on germination and early growth of groundnut. Journal of Plant Nutrition 26: 1247-1262.

Nosko, P. \& Kershaw, K.A. 1987. The effect of aluminium on seed germination and early seedling establishment, growth, and respiration of white spruce (Picea glauca). Canadian Journal of Botany 66: 2305-2310.

Olsson, B.A. \& Kellner, O. 2002. Effects of soil acidification and liming on ground flora establishment after clearfelling of Norway spruce in Sweden. Forest Ecology and Management 158: 127-139.

Osborne, D.J. 1983. Biochemical control systems operating in the early hours of germination. Candian Journal of Botany 61:3568-3590.

Perez, S.C.J.G.A. 2004. Dormência embrionária. In: A.G. Ferreira \& F. Borghetti (orgs.). Germinação: do básico ao aplicado. Artmed, Porto Alegre, pp. 125-135.

Plieth, C., Sattelmcher, B., Hansen, U. \& Knight, M.R. 1999. Low-pH-mediated elevations in cytosolic calcium are inhibited by aluminium: a potencial mechanism for aluminium toxicity. The Plant Journal 18: 643-650.

Quagliano, J.V. \& Vallarino, L.M. 1973. Química. 3 ed. Guanabara, Rio de Janeiro.

Raij, B.V. 1987. Avaliação da fertilidade do solo. 3 ed. Potafos, Piracicaba.

Redmann, R.E. \& Abouguendia, Z.M. 1979. Germination and seedling growth on substrates with extreme $\mathrm{pH}$ laboratory evaluation of buffers. Journal of Applied
Ecology 16: 901-907.

Resende, M., Lani, J.L. \& Rezende, S.B. 2002. Pedossistemas da Mata Atlântica: considerações pertinentes sobre a sustentabilidade. Revista Árvore 26:261-269.

Roem, W.J., Klees, H. \& Berendse, F. 2002. Effects of nutrient addition and acidification on plant species diversity and seed germination in heathland. Journal of Applied Ecology 39: 937-948.

Rout, G.R., Samantaray, S. \& Das, P. 2001. Aluminium toxicity in plants: a review. Agronomie 21: 3-21.

Santos, V.L.M., Calil, A.C., Ruiz, H.A., Alvarenga, E.M. \& Santos, C.M. 1992. Efeito de estresse salino e hídrico na germinação e vigor das sementes de soja. Revista Brasileira de Sementes 14: 190-200.

Scherbatskoy,T., Klein, R.M. \& Badger, G.J. 1987. Germination response of forest tree seed to acidity and metal ions. Environmental and Experimental Botany 27: 157-164.

Stubbendieck, J. 1974. Effect of pH on germination of three grass species. Journal of Range Management 27: 78-79.

Tamás, L., Simonovicova, J., Huttová, J. \& Mistrik, I. 2004. Aluminium stimulated hydrogen peroxide production of germinating barley seeds. Environmental and Experimental Botany 51:281-288.

Tamás, L., Budikova, S., Simonovicova, J., Huttová, J., Siroka, B. \& Mistrik, I. 2006. Rapid and simple method for Al-toxicity analysis in emerging barley roots during germination. Biologia Plantarum 50: 87-93.

Taylor, J.G., McDonald-Stephens, J.L., Hunter, D.B., Bertsh, P.M., Elmore, D., Rengel, Z. \& Reid, R.J. 2000. Direct measurement of aluminium uptake and distribution in single cells of Chara corallina. Plant Physiology 123: 987-996.

Torres, S.B., Viera, E.L. \& Marcos Filho, J. 2000. Efeitos da salinidade na germinação e no desenvolvimento de plântulas de pepino. Revista Brasileira de Sementes 22: 39-44.

Vitorello, V.A., Capaldi, F.R. \& Stefanuto, V.A. 2005. Recent advances in aluminium toxicity and resistance in higher plants. Brazilian Journal of Plant Physiology 17: 129-143.

Wang, Y., Stass, A. \& Horst, W.J. 2004. Apoplastic binding of aluminum is involved in silicon-induced amelioration of aluminum toxicity in maize. Plant Physiology 136: 3762-3770.

Yamamoto, Y., Kobayashi, Y., Devi, S.R., Rikiishi, S. \& Matsumoto, H. 2002. Aluminium toxicity is associated with mitocondrial dysfunction and the production of reative oxigen species in plant cells. Plant Physiology 128: 63-72.

Zammit, C.A. \& Zedler, P.H. 1988. Germination response to extreme acidity: impact of simulated acid deposition from a single shuttle launch. Environmental and Experimental Botany 28: 73-81. 